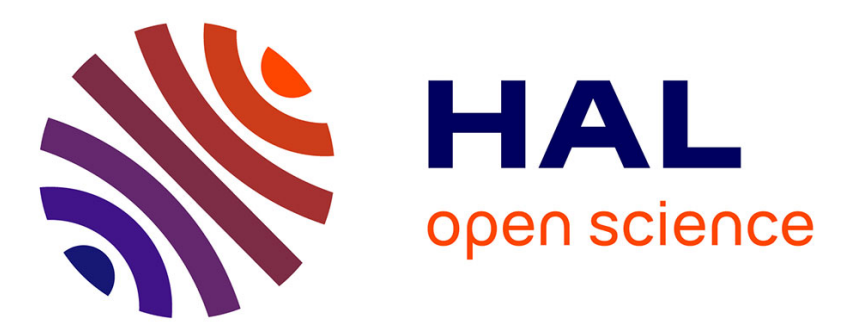

\title{
Microbial diversity of supra- and subgingival biofilms on freshly colonized titanium implant abutments in the human mouth
}

\author{
W. Heuer, M. Stiesch, W. R. Abraham
}

\section{- To cite this version:}

W. Heuer, M. Stiesch, W. R. Abraham. Microbial diversity of supra- and subgingival biofilms on freshly colonized titanium implant abutments in the human mouth. European Journal of Clinical Microbiology and Infectious Diseases, 2010, 30 (2), pp.193-200. 10.1007/s10096-010-1068-y . hal00630266

\section{HAL Id: hal-00630266 \\ https://hal.science/hal-00630266}

Submitted on 8 Oct 2011

HAL is a multi-disciplinary open access archive for the deposit and dissemination of scientific research documents, whether they are published or not. The documents may come from teaching and research institutions in France or abroad, or from public or private research centers.
L'archive ouverte pluridisciplinaire HAL, est destinée au dépôt et à la diffusion de documents scientifiques de niveau recherche, publiés ou non, émanant des établissements d'enseignement et de recherche français ou étrangers, des laboratoires publics ou privés. 
1 Microbial diversity of supra- and subgingival biofilms on freshly colonized titanium implant abutments in 2 the human mouth

3

$4 \quad$ W. Heuer ${ }^{1}$, M. Stiesch ${ }^{1}$, W. R. Abraham $^{2}$

5

$6{ }^{1}$ Department of Prosthetic Dentistry and Biomedical Materials Science, Hannover Medical School, Hannover,

7 Germany

$8{ }^{2}$ Helmholtz Centre for Infection Research, Chemical Microbiology, Braunschweig, Germany

9

10

11 Correspondence to:

12 Dr. Wolf-Rainer Abraham

13 Helmholtz Centre for Infection Research

14 Chemical Microbiology

15 Inhoffenstrasse 7

1638124 Braunschweig, Germany

17 Tel.: +49-531-6181-4300/-4226

18 Fax: +49-531-6181-4699

19 E-mail: Wolf-Rainer.Abraham@helmholtz-hzi.de

20

21 


\section{Abstract:}

23 Background: Supra- and subgingival biofilm formation is considered to be mainly responsible for early implant 24 failure caused by inflammations of periimplant tissues. Nevertheless, little is known about the complex microbial 25 diversity and interindividual similarities around dental implants.

26 Objectives: An atraumatic assessment of the diversity of microbial communities around titanium implants by 27 single strand conformation polymorphism (SSCP) analysis of the 16S rRNA gene amplicons and subsequent 28 sequence analysis.

29 Methods: Samples of adherent supra- and subgingival peri-implant biofilms were collected from ten patients.

30 Additionally, samples of sulcusfluid were taken at titanium implant abutments and remaining teeth. The bacteria 31 in the samples were characterized by SSCP and sequence analysis.

32 Results: A high diversity of bacteria varying between patients and within one patient with location was found. 33 Bacteria characteristic for sulcusfluid and supra- and subgingival biofilm communities were identified. 34 Sulcusfluid of the abutments showed higher abundance of Streptococcus species than from residual teeth. 35 Prevotella and Rothia species frequently reported from the oral cavity were not detected at the abutments 36 suggesting a role as late colonizers.

37 Conclusion: Different niches in the human mouth are characterized by specific groups of bacteria. Implant 38 abutments are a very valuable approach to study dental biofilm development in vivo.

\section{Keywords:}

43 Oral implants, single strand conformation polymorphism, microbial diversity, implant abutments, biofilm, 44 microbial communities 


\section{Introduction:}

The clinical success of osseointegrated oral implants led to extended application. Today many conventionally prosthetic treatments have been replaced by implant supported prosthetic supraconstructions. From a clinical viewpoint this fact is supported by multitudinous studies which analyzed structural and functional improvements of the implant surface. While the problem of primary osseointegration is solved in a high quality manner, inflammation of peri-implant tissues by the presence of bacterial biofilms is considered currently as one of the principle problems in oral implantation and, therefore, responsible for early implant failure. This early implant failures are clinically characterized by inflammation of the peri-implantary mucosa (Figure 1a) and a subsequent destruction of the peri-implantary bone (Figure 1b).

The early processes of biofilm formation, like generation of an acquired pellicle by salivary biopolymers or enzymes and adherence of initial microorganisms, is described as is the relationship between biofilm formation and periodontitis or periimplantitis. For example, Streptococcus mitis, S. sanguinis and $S$. oralis are known to create the pre-conditions for the accumulation of gram-negative anaerobic bacteria [1-5]. Several studies were able to indicate, that during periimplant biofilm formation the microbial composition shifted towards a higher proportion of such gram-negative anaerobic microbiota [6-10]. However, these previously studies of microorganisms associated with diseases relied heavily upon cultivation or DNA checkerboard hybridization methods. The applied techniques are associated with the main disadvantages of a specific bacterial identification or time-consuming and fault-prone cultivation [11]. This led to the identification of several species as putative periodontopathogens based on frequency of their isolation in lesion sites. Among these are Aggregatibacter actinomycetemcomitans, Porphyromonas gingivalis, Prevotella intermedia, Bacteroides forsythus, Treponema denticola, Fusobacterium nucleatum, Parvimonas micra, Campylobacter rectus, Eikenella corrodens and Selenomonas sputigena [12-15]. However, concentrating only on those bacteria which can currently be cultivated and ignoring particularly those which cultivation fails to capture [16] will not give a complete picture of infections leading to periodontitis or periimplantitis [17]. Because of these limitations, it is also difficult to acquire a complete understanding of the dynamic changes of oral microbes as dental biofilms turn from harmless ones into detrimental microbial communities. Answers to this challenge are cultureindependent methods to monitor microbial communities over space and time.

Therefore, the objective of the present study was to assess the diversity of microbial communities, by culture-independent methods, of initial periimplant biofilms in supra- and subgingival areas, to compare them with those of the sulcus fluid and to identify microbial communities posing potential problems for infections. In 
addition, a sample of sulcusfluid was taken at one remaining tooth in the same jaw to evaluate cross-infections between implants and teeth in the initial phase of biofilm formation.

\section{Material and methods:}

Subjects:

The present study was approved by the ethics committee of Hannover Medical School (No. 3791). The examination was performed with the understanding and written consent of each patient.

Qualitative analysis was based on 10 healing abutments which were inserted for 14 days into 10 patients, 6 women and 4 men, aged between 60 and 83 years (mean 70 years \pm 6.7 years). Patients were selected to fulfil the following inclusion criteria: no systemic illness, no smoking, no pregnancy, no active periodontitis (probing pocket depth $\leq 4 \mathrm{~mm}$ ), no pharmacological treatment or antibiotic therapy during or up to four months before the study. At the day of abutment insertion all patients received dental hygiene instructions but no professional tooth cleaning was performed during the observation period.

All patients were partially edentulous and had at least one oral two-piece implant made of titanium (Astra Tech, Mölndal, Sweden), which had been inserted three months before investigation. Two weeks after abutment surgery, the previously existing abutments were removed and new sterile healing abutments (Astra Tech, Mölndal, Sweden) for the analysis were inserted (Figure 2). Thereby no trimming of surrounding gingiva was performed.

Sampling:

Two weeks after insertion of the new sterile healing abutments, samples of adherent biofilm and crevicular fluid were taken. The periimplant saliva was removed by use of an air spray and cotton rolls. First, samples of crevicular fluid were taken with sterile paper points at abutments and remaining teeth. Afterwards, samples of adherent supragingival biofilm on the abutments were taken with sterile sponges. The samples of adherent subgingival biofilm could be collected after abutment removal. All samples were stored in sample tubes (Eppendorf $\mathrm{AG}$ ) at $-80^{\circ} \mathrm{C}$.

\section{DNA analysis:}


DNA was extracted using the Fast-DNA-Spin-Kit for soil (Bio 101, CA, USA) following the instructions of the manufacturer. The primers chosen for the amplification of bacterial 16S rRNA genes were

107 forward primer Com1 (5'CAGCAGCCGCGGTAATAC3') and reverse primer Com2-Ph

108 (5'CCGTCAATTCCTTTGAGTTT3' with 5'-terminal phosphate group) as published by Schwieger and Tebbe

109 [18]. To obtain single-stranded DNA the phosphorylated strand of the PCR products was digested by lambda

110 exonuclease (New England Biolabs, Schwalbach, Germany) following the protocol of Schwieger and Tebbe, and

111 further purified using the Mini-elute-Kit (Qiagen, Hilden, Germany) as recommended by the manufacturer, and

112 the remaining single stranded DNA was dried under vacuum. The DNA was then resuspended in denaturating

113 SSCP loading buffer ( $47.5 \%$ formamide, $5 \mathrm{mM}$ sodium hydroxide, $0.12 \%$ bromophenol blue and $0.12 \%$ xylene

114 cyanol), incubated at $95^{\circ} \mathrm{C}$ for 2 min and immediately cooled on ice. After $5 \mathrm{~min}$, samples were loaded onto the

115 gels and subjected to electrophoresis. The samples were electrophoresed in a MDE gel $(9 \mathrm{ml} 2 \mathrm{x}$ MDE (FMC

116 Bioproducts, Rockland, Maine), $3 \mathrm{ml}$ 10x TBE buffer, $18 \mathrm{ml}$ bidest. water, 10\% APS $120 \mu 1$ and $12 \mu 1$ TEMED).

117 Gels $(21 \mathrm{~cm})$ were cast (spacers of $0.5 \mathrm{~mm}$ ) and run with $1 \mathrm{x}$ TBE buffer. Gels were run at $400 \mathrm{~V}$ for $16 \mathrm{~h}$ at

$11820^{\circ} \mathrm{C}$ in a Macrophor electrophoresis unit (LKB Bromma, Sweden) and subsequently silver stained [19].

120 Sequence analysis:

121 Single bands were excised from the gels and eluted in extraction-buffer (10 mM Tris-buffer, $5 \mathrm{mM} \mathrm{KCl}$, $1221.5 \mathrm{mM} \mathrm{MgCl} 2 \times 6 \mathrm{H} 2 \mathrm{O}, 0.1 \%$ Triton X 100, $\mathrm{pH} 9.0)$ at $95^{\circ} \mathrm{C}$ for $15 \mathrm{~min}$. Extracts were centrifuged $(12000 \times \mathrm{g}$, $1231 \mathrm{~min}$ ) and the DNA in the supernatant fluid was used for PCR with the primers described above. The PCR124 product was cleaned (Mini-elute-Kit, Qiagen, Hilden, Germany) and sequenced with a sequencing kit 125 (DYEnamic ET Terminator cycle sequencing kit by Amersham Biosciences, Freiburg, Germany) and both 126 primers. The product was cleaned with the Dye Ex Spin Kit (Qiagen, Hilden, Germany) and the sequence 127 analyzed on an ABI PRISMTM 337 DNA-Sequencer and 3100 Genetic Analyser. Comparisons of the sequences 128 were performed using the BLAST program and the databases of EMBL [20] and GenBank [21]. The 129 phylogenetic analysis was done using the MUSCLE version 3.6 software for sequence alignments [22]. Tree 130 topologies were reconstructed with neighbour-joining algorithm (complete deletion of gaps/missing data, 131 maximum composite likelihood model, bootstrap: 1000 replicates) (Figure 3) with the software MEGA 4 [23]. 132 All reference sequences used in the tree are from validated bacterial species: each has been cultured, 133 characterized, deposited with at least two recognized culture collections, and named under the procedure 134 described in the International Bacteriological Code of Nomenclature (ICNB), 1990 revision [24].The sequences 
135 of the oral rDNA bands obtained from patients 1 to 10 (31 sequences, indicated in Figure 3) have been deposited 136 in the GenBank database under accession numbers FN870024-FN870053 and FR666873.

138 Statistics:

139 Statistical analyses were done using the STATISTICA 6 software. For correlation analysis and 140 discriminate analysis the presence/absence of a species was used. Discriminant analysis was performed applying 141 the forward stepwise method setting the tolerance to minimum $\left(10^{-10}\right)$.

142

\section{Results}

144 All samples showed a large number of SSCP-bands and, hence, possess a high diversity of bacteria 145 varying between patients and within one patient with location (Figure 4). Sequence analyses of 101 SSCP-bands 146 led to the identification of 31 different bacterial taxa belonging to 5 different bacterial phyla (Firmicutes, 147 Actinobacteria, Proteobacteria (Beta-, Gamma- and Epsilon-), Bacteroidetes and Fusobacteria). Remarkable 148 were the diversity of Veillonella, Streptococcus, Parvimonas, Fusobaterium and Neisseria species detected. 149 Species have only been identified down to the species level if they matched exactly with the sequence of the type 150 strain (Figure 3). In the genus Veillonella gene sequences matching those of Veillonella parvula (Veillonella 151 parvula 54-5) and Veillonella atypica (Veillonella atypica 133-5) could be identified. A third sequence 152 (Veillonella sp. 112-3) was closer related to Veillonella dispar. As has been expected, many biofilm bacteria fell 153 into the genus Streptococcus. Here Streptococcus mitis 42-1 and Streptococcus intermedius 63-1 could be 154 identified together with two unknown Streptococcus species which were related to Streptococcus intermedius 155 and Streptococcus constellatus (Streptococcus sp. 41-2 and 113-3). No sequence belonging to Streptococcus 156 mutans was found. The genus Fusobacterium comprises strictly anaerobic bacteria and species of this genus are 157 well known from the human mouth. The species Fusobacterium naviforme 72-3 and Fusobacterium canifelinum $158 \quad 113-8$ were identified from the corresponding SSCP amplicons together with a third Fusobacterium sequence 159 (Fusobacterium sp. 63-3) which was related to Fusobacterium naviforme. As for the former two species of the 160 genus Neisseria have been reported as common members of dental biofilms in humans and Neisseria mucosa 161 133-2 was found together with the unknown Neisseria species 71-2 related to Neisseria polysaccharea.

162 Parvimonas micra, widely distributed in human dental biofilms, was also detected in this study (Parvimonas 163 micra 52-1). From one patient however, two distinct Parvimonas sequences have been identified (Parvimonas 164 sp. 72-1 and 72-3) belonging to two undescribed Parvimonas species (Figure 3). 

identified. Significant correlations were found between Veillonella species 112-3 and Neisseria species 71-2, Haemophilus parainfluenzae 112-5 and Campylobacter sp. 113-6, between Veillonella parvula 54-5 and Oribacterium species 54-3 and Centipeda periodontii 54-1 and between Veillonella sp. 133-5 and Campylobacter gracilis 54-7 and Selenomonas noxia 134-1. Streptococcus mitis 42-1 was significantly

170 associated with Lautropia mirabilis 74-1, while the occurrence of Streptococcus intermedius 63-1 correlated with that of Campylobacter sp. 113-6. Fusobacterium canifelinum is closely related to Fusobacterium nucleatum which is known to have many interactions with other bacteria in dental plaques, but we found only a significant correlation between its occurrences with the two Campylobacter species.

We addressed the question whether the microbial communities are controlled by the individual host or the environment controls the composition of the community. To achieve this goal we used the bacteria detected in a sample to discern between the different types of samples. Discriminant analysis is used to find a combination of features (here bacteria species) which characterize or separate classes of objects (here sampling sites or patients). The resulting combination can be used to reduce the dimensionality. We applied discriminant analyses to identify such correlations and could not find microbial communities specific for the individual patients (data not shown). However, discriminant analyses identified occurrences of Lactobacillus delbrueckii 92-2, Parvimonas sp. 72-1, Haemophilus parainfluenzae 112-5 and Streptococcus mitis $42-1$ as discriminative between the subgingival bacteria and the other samples. The occurrences of Parvimonas micra 52-1 and

183 Neisseria mucosa 133-2 were characteristic for the supragingival microbial communities, while those of the sulcusfluid from the abutments were characterized by the presence of Burkholderia sp. 113-1 (Figure 5a). In

185 figure $5 \mathrm{~b}$ the contribution of every discriminative strain to the plot shown in figure $5 \mathrm{a}$ was plotted for the first two coefficients factors. This presentation allows the fast identification of strains to a given sample set, e. g.

187 Parvimonas micra 52-1 and Neisseria mucosa 133-2 contributed most to supragingival biofilms while Parvimonas sp. 72-1 was characteristic for subgingival biofilms. For the sulcusfluid from the residual teeth no

189 discriminative bacteria could be identified as expected from the central position of this group in figure 5a.

190 Comparing the sulcusfluid around the abutments and around the residual teeth only small differences in the 191 microbial diversity was seen. One remarkable difference, however, was the higher diversity and the much higher

192 frequency of Streptococcus sequences found in the sulcusfluid around the abutments compared to that from 193 residual teeth.

\section{Discussion}


The use of healing abutments to study the microbial diversity of initial biofilms on oral implant abutments using an unspecific molecular biological detection method allows an in-vivo analysis of biofilms in

198 supra and subgingival areas along oxic-anoxic gradients. The anaerobic environment enables realistic formation 199 of the same biofilm as during development of mucositis or periimplantitis. The advantage to remove healing abutments atraumatically for sampling adherent bacteria in subgingival areas without contaminating the sample with supragingival microbiota was an important precondition for a realistic comparison of supra- and subgingival biofilm compositions. In the present study a short term investigation of biofilm formation on healing abutments was performed over a period of 14 days. The analysis was performed over this specific period to display the realistic and typical microorganisms in the initial phase of biofilm formation. Furthermore previous investigations approved microbiota around implants to remain unchanged for six months after a comparable period [25]. In recent studies, a similar method directed to the typical periodontal pathogens Aggregatibacter actinomycetemcomitans or Porphyromonas gingivalis in the periimplant crevicular fluid was used [26, 27]. However, structural differences between healing abutments and implant retained prostheses have to be considered while interpreting the results. Implant anchored prostheses like crowns or bridges exhibit an anatomic form with typical plaque retentive sites. Furthermore, a gap between the definitive abutments and the dental

211 prostheses can boost the biofilm formation because of their modular configuration. However, an analysis of 212 initial adherent biofilms along oxic-anoxic gradients is not possible with implant retained dental prostheses 213 because sampling of adherent bacteria in subgingival areas without removal of the construction is leading to a 214 contamination with supragingival microbiota in the majority of cases.

215 In the present study several species of the genera Veillonella, Streptococcus, Parvimonas, Fusobaterium 216 and Neisseria were detected all of them well known from dental plaques. Not all of them fitted to the 16S rRNA 217 gene sequences reported from the type strains of accepted species. However, the identification of the Veillonella 218 species is complicated as it has been reported that as least some Veillonella species have a rather high intra219 chromosomal heterogeneity between their four rRNA gene copies [28]. No Streptococcus mutans sequences 220 were found, however, the essential role of Streptococcus mutans in the caries process has been questioned [29] as some strains of Streptococcus oralis exhibited levels of caries induction in rats that were close to those of

222 Streptococcus mutans [30]. Streptococci are the principal group of the early colonizing bacteria showing 223 interactions with a number of other bacteria. One example is a metabolic interaction with Veillonella species, 224 which coaggregate with Streptococci [31]. In this food chain Veillonella uses lactic acid produced by the 225 Streptococci as an end product of carbohydrate fermentation [32]. Streptococcus species were detected in $75 \%$ 
and Veillonella species in 50\% of the patients. Only in one patient no Streptococcus but Veillonella parvula

227

228

229

230

231

232

233

234

235

236

237

238

239

240

241

242

243

244

245

246

247

248

249

250

251

252

253

254

255

256 could be found.

Species of the genus Fusobacterium are obligate anaerobes and implicated in the pathogenesis of periodontal disease. However, this organism has also been frequently identified in high numbers in healthy adults. Consequently it was found in six out ten patients. The diversity of Fusobacterium species between the different patients and also between the different locations was high. Such diversity has also been observed at the clonal level of $F$. nucleatum isolates [33]. Interestingly, in this study also a large dynamic between the clones could be shown. Furthermore, it is known from $F$. nucleatum that is a typically middle colonizer of dental surfaces showing many interactions with the surrounding bacteria cells [34]. Both observations can explain the diversity observed in our study but not the absence of Fusobacterium strains in some patients. This finding points to alternative routes to anaerobic communities and plaque formation not involving Fusobacterium.

Well known primary colonizers are species of the genus Neisseria and found in the majority of the patients but in two out of ten patients they could not be detected. Again it is reasonably to assume that Neisseria is not essential for the primary colonization of dental implants and can be substituted by other species. In addition to Neisseria many of the bacteria identified in this study including the Burkholderia species were also reported from the initial colonization of enamel [35], childhood caries [36] and in periodontal pockets [37]. Interestingly, no Prevotella or Rothia species was detected which were reported to be rather abundant in a recent study on the oral microbiota of 10 individuals with healthy oral tissues [38]. It is tempting to speculate that these bacteria appear late in the oral biofilm formation and were, therefore, not observed in our two-weeks-study. Such an information can only obtained with methods which are at least "semiquantitative" but are hard to deduce from a metagenomic approach [39]. A further advantage of the culture-independent approach applied here is the detection of novel species, e. g. Oribacterium sp. 54-3. According to the gene databases such strain has never been detected before and judging from its remote relatedness to Oribacterium sinus it may well belong to a still undescribed genus.

Having assessed the microbial diversity of young biofilms in the human mouth it is interesting to compare the findings with detrimental biofilms reported in the literature [40]. Socransky and coworkers assessed the microbial diversity of a large number of plaque samples and correlated it with the clinical assessment [15]. Multivariate analyses revealed five groups of bacteria increasingly related to periodontitis. We compared this finding with our results and found that none of the species in the group strikingly related to periodontal disease was detected in our study. This indicates no forms of gingivitis or periodontitis. Beside pathogens related to dental diseases other pathogens were found in a few samples, e. g. Neisseria mucosa, Actinomyces israelii or 
Haemophilus parainfluenzae. The detection of Haemophilus parainfluenzae fits to the suggestion that typical

258

259

260

261

262

263

264

265

266

267

268

269

270

271

272

273

274

275

276

277

278

279

280

281

282

283

284

285

286

287

respiratory pathogens may colonize the teeth of hospitalized intensive care and nursing home patients [41].

The occurrences of some bacteria were found to be discriminative for some sites. Streptococcus mitis and Lactobacillus delbrueckii contributed together with Parvimonas sp. 72-1 to the discrimination of subgingival biofilm communties while Neisseria mucosa and Parvimonas micra where mainly contributing to the discrimination of supragingival biofilms. This also confirms their role as primary colonizers. Our results confirmed earlier findings [42] but extended the number of site specific bacteria considerably. We also showed that Prevotella and Rothia species, abundant in the oral cavity of healthy individuals, are not members of the young biofilm communities. Concerning the experimental set-up used our results show as well that healing abutments can be used as a convenient model to study initial colonization of implants under natural conditions in humans.

\section{Acknowledgements}

We are indebted to Jennifer Knaak for her excellent technical assistance. This work was supported by a grant from the German Federal Ministry for Science, Education and Research (Project No. 01 KI 07 96) and by the German Research Foundation (DFG-SFB Collaborative Research Center 599).

\section{References:}

1. Slots J (1977) The predominant cultivable microflora of advanced periodontitis. Scand J Dent Res 85:114-121.

2. Loe H, Theilade E, Jensen SB (1965) Experimental gingivitis in man. J Periodontol 36:177-187.

3. Quirynen M, Vogels R (2002) [Clinical relevance of surface characteristics on the formation of plaque on teeth and implants]. Ned Tijdschr Tandheelkd 109:422-429.

4. Hannig M (1997) Transmission electron microscopic study of in vivo pellicle formation on dental restorative materials. Eur J Oral Sci 105:422-433.

5. Slots J (1977) Microflora in the healthy gingival sulcus in man. Scand J Dent Res 85:247-254.

6. Berglundh T, Lindhe J, Ericsson I, Liljenberg B (1992) Enhanced gingivitis in the deciduous and permanent dentition. An experimental study in the dog. J Clin Periodontol 19:135-142.

7. Berglundh T, Lindhe J, Marinello C, Ericsson I, Liljenberg B (1992) Soft tissue reaction to de novo plaque formation on implants and teeth. An experimental study in the dog. Clin Oral Implants Res 3:18. 
288 8. Leonhardt A, Berglundh T, Ericsson I, Dahlen G (1992) Putative periodontal pathogens on titanium implants and teeth in experimental gingivitis and periodontitis in beagle dogs. Clin Oral Implants Res $3: 112-119$

$2919 . \quad$ Ericsson I, Berglundh T, Marinello C, Liljenberg B, Lindhe J (1992) Long-standing plaque and gingivitis at implants and teeth in the dog. Clin Oral Implants Res 3:99-103.

10. Abrahamsson I, Berglundh T, Lindhe J (1998) Soft tissue response to plaque formation at different implant systems. A comparative study in the dog. Clin Oral Implants Res 9:73-79; Erratum 9:281.

11. Lau L, Sanz M, Herrera D, Morillo JM, Martin C, Silva A (2004) Quantitative real-time polymerase chain reaction versus culture: a comparison between two methods for the detection and quantification of Actinobacillus actinomycetemcomitans, Porphyromonas gingivalis and Tannerella forsythensis in subgingival plaque samples. J Clin Periodontol 31:1061-1069.

12. Slots J, Rams TE (1991) New views on periodontal microbiota in special patient categories. J Clin Periodontol 18:411-420.

13. Socransky SS, Haffajee AD (1992) The bacterial etiology of destructive periodontal disease: current concepts. J Periodontol 63:322-331.

14. Wolff L, Dahlen G, Aeppli D (1994) Bacteria as risk markers for periodontitis. J Periodontol 65:498510.

15. Socransky SS, Haffajee AD, Cugini MA, Smith C, Kent RL, Jr. (1998) Microbial complexes in subgingival plaque. J Clin Periodontol 25:134-144.

17. Kroes I, Lepp PW, Relman DA (1999) Bacterial diversity within the human subgingival crevice. Proc

18. Schwieger F, Tebbe CC (1998) A new approach to utilize PCR-single-strand-conformation polymorphism for 16S rRNA gene-based microbial community analysis. Appl Environ Microbiol 64:4870-4876. polyacrylamide gels. Anal Biochem 196:80-83; Erratum 198:217. collection: a community of data resources. Nucleic Acids Res 38:D1-4. 
318 21. Benson DA, Karsch-Mizrachi I, Lipman DJ, Ostell J, Wheeler DL (2008) GenBank. Nucleic Acids Res $319 \quad 36: D 25-30$.

320 22. Edgar RC (2004) MUSCLE: multiple sequence alignment with high accuracy and high throughput. $321 \quad$ Nucleic Acids Res 32:1792-1797.

322 23. Kumar S, Nei M, Dudley J, Tamura K (2008) MEGA: a biologist-centric software for evolutionary 323 analysis of DNA and protein sequences. Brief Bioinform 9:299-306.

324 24. Sneath PHA (1992) International code of nomenclature of bacteria: bacteriological code, 1990 revision. $325 \quad$ ASM Press

326 25. De Boever AL, De Boever JA (2006) Early colonization of non-submerged dental implants in patients 327 with a history of advanced aggressive periodontitis. Clin Oral Implants Res 17:8-17.

328 26. Elter C, Heuer W, Demling A, Hannig M, Heidenblut T, Bach FW, Stiesch-Scholz M (2008) Supra329 and subgingival biofilm formation on implant abutments with different surface characteristics. Int $\mathrm{J}$ Oral Maxillofac Implants 23:327-334.

331 27. Heuer W, Elter C, Demling A, Neumann A, Suerbaum S, Hannig M, Heidenblut T, Bach FW, StieschScholz M (2007) Analysis of early biofilm formation on oral implants in man. J Oral Rehabil 34:377382.

28. Marchandin H, Teyssier C, Simeon De Buochberg M, Jean-Pierre H, Carriere C, Jumas-Bilak E (2003)

29. Beighton D (2005) The complex oral microflora of high-risk individuals and groups and its role in the

30. Willcox MD, Drucker DB, Green RM (1987) Relative cariogenicity and in-vivo plaque-forming ability

32. Mikx FH, van der Hoeven JS (1975) Symbiosis of Streptococcus mutans and Veillonella alcalescens in mixed continuous cultures. Arch Oral Biol 20:407-410.

345 33. Suchett-Kaye G, Decoret D, Barsotti O (1998) Clonal analysis by ribotyping of Fusobacterium nucleatum isolates obtained from healthy young adults with optimal plaque control. J Periodontal Res 33:179-186. 
348 34. Periasamy S, Kolenbrander PE (2010) Central role of early colonizer Veillonella sp. in establishing multispecies biofilm communities with initial, middle and late colonizers of enamel. J Bacteriol ahead of print, doi:10.1128/JB.01631-09.

35. Diaz PI, Chalmers NI, Rickard AH, Kong C, Milburn CL, Palmer RJ, Jr., Kolenbrander PE (2006) Molecular characterization of subject-specific oral microflora during initial colonization of enamel. Appl Environ Microbiol 72:2837-2848.

354 36. Becker MR, Paster BJ, Leys EJ, Moeschberger ML, Kenyon SG, Galvin JL, Boches SK, Dewhirst FE, Griffen AL (2002) Molecular analysis of bacterial species associated with childhood caries. J Clin

357 37. Paster BJ, Boches SK, Galvin JL, Ericson RE, Lau CN, Levanos VA, Sahasrabudhe A, Dewhirst FE (2001) Bacterial diversity in human subgingival plaque. J Bacteriol 183:3770-3783.

359 38. Bik EM, Long CD, Armitage GC, Loomer P, Emerson J, Mongodin EF, Nelson KE, Gill, SR, FraserLogget CM, Relman DA (2010) Bacterial diversity in the oral cavity of 10 healthy individuals. ISME J 2010:1-13.

39. Zaura E, Keijser BJ, Huse SM, Crielaard W (2009) Defining the healthy "core microbiome" of oral microbial communities. BMC Microbiol 9:259.

364 40. Zijnge V, Harmsen HJ, Kleinfelder JW, van der Rest ME, Degener JE, Welling GW (2003) Denaturing gradient gel electrophoresis analysis to study bacterial community structure in pockets of periodontitis patients. Oral Microbiol Immunol 18:59-65.

367 41. Scannapieco FA (1999) Role of oral bacteria in respiratory infection. J Periodontol 70:793-802.

368 42. Paster BJ, Olsen I, Aas JA, Dewhirst FE (2006) The breadth of bacterial diversity in the human periodontal pocket and other oral sites. Periodontol 2000 42:80-87. 
372 Figure 1: Clinical signs of periimplantitis with an inflammation of the peri-implantary mucosa (arrows) (a) and a

373 subsequent destruction of the peri-implantary bone with the typical signs of radiographic bone loss around the

374 dental implant (arrows) (b).

375

376

Figure 2: New sterile Healing abutment (regio 12) in situ.

Figure 3: Unrooted phylogentic tree based on 16S rRNA gene sequences obtained by sequencing SSCP bands values above $50 \%$ are shown. Only sequences with more than 350 unambiguously determined base pairs were included. Numbers in bold stand for sequences of SSCP bands deposited at GenBank. Scale bar represents 5 nucleotide substitutions per 100 bases.

383

384 Figure 4: SSCP samples from 5 patients; $\mathrm{sp}=$ supragingival, $\mathrm{sb}=$ subgingival, $\mathrm{ab}=$ sulcusfluid from abutment, $385 \mathrm{rt}=$ sulcusfluid from residual teeth. Numbered bands are $1=$ Neisseria mucosa, $2=$ Veillonella parvula, $3=$

386 Burkholderia sp. 113-1, 4 = Marinobacter santoriniensis, 5= Parvimonas micra, $6=$ Corynebacterium sp. 51-2,

$3877=$ Leptotrichia sp. 51-3, $8=$ Klingella sp. 112-2, $9=$ Campylobacter gracilis, $10=$ Centipeda periodontii, $11=$

388 Oribacterium sp. 54-3, 12 = Fusobacterium nucleatum, 13 = Fusobacterium sp. 63-3, 14 = Parvimonas sp. 72-1,

$38915=$ Parvimonas sp. 72-2, 16 = Fusobacterium naviforme, $17=$ Lautropia mirabilis, $18=$ Neisseria sp. 71-2, 19

390 = Streptococcus mitis, 20 = Lactobacillus delbrueckii, 21 = Streptococcus intermedius, 22 = Capnocytophaga

391 sputigena.

392

393 Figure 5: Discriminant analysis between the four sampling sites and the presence/absence of their bacteria. Only

394 roots 1 and 2 are shown. 5a (left): Plot of the four different sample types; circle: supragingival biofilms (solid 395 ellipse), square: subgingival biofilms (dashed ellipse), rhomb: sulcusfluids of the abutments (mixed dashed 396 ellipse), triangle: sulcusfluids of the residual teeth (solid ellipse). 5b (right): factor loadings of the bacteria 397 discriminating the four groups. 
398

399 Figures:

400 Figure $1 \mathrm{a} / \mathrm{b}$ :

401

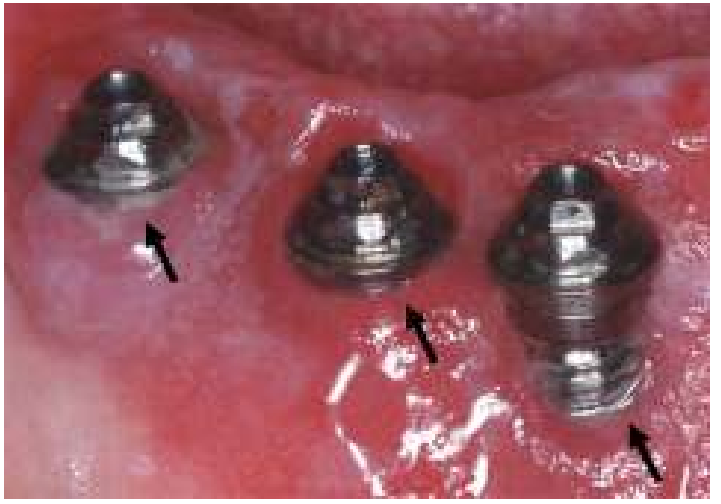

402

403

404

405

406

407

408

409 Figure 2:

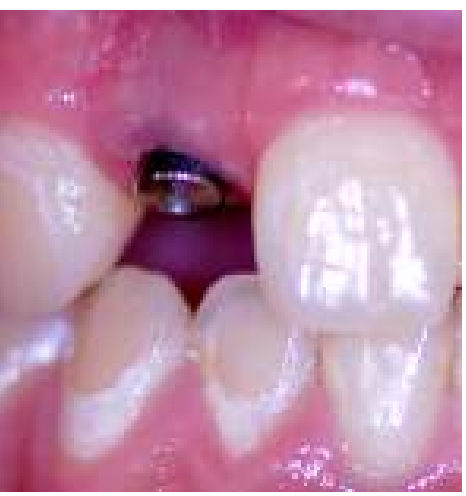

411

412

413

414

415 


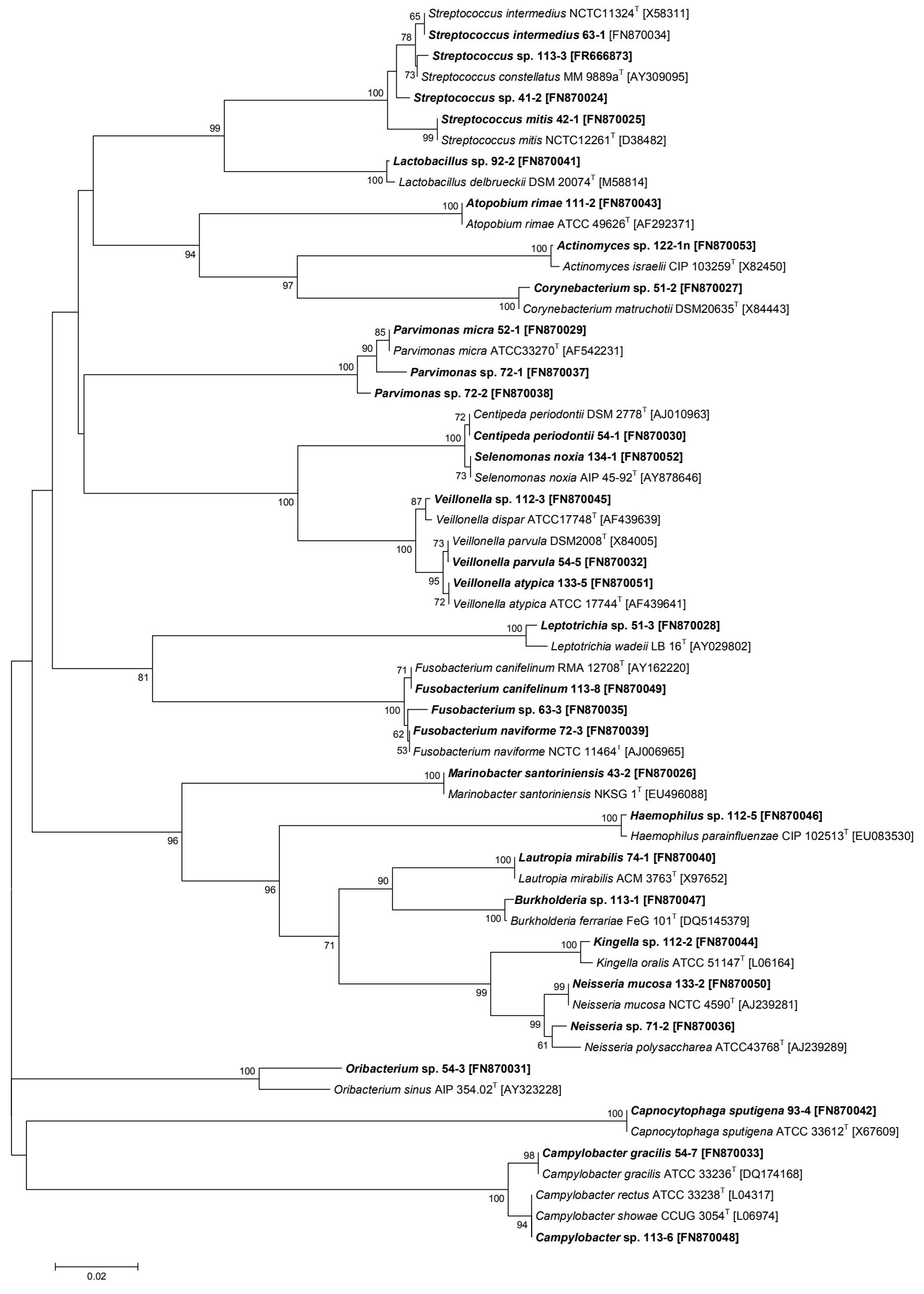


418 Figure 4:

419

420

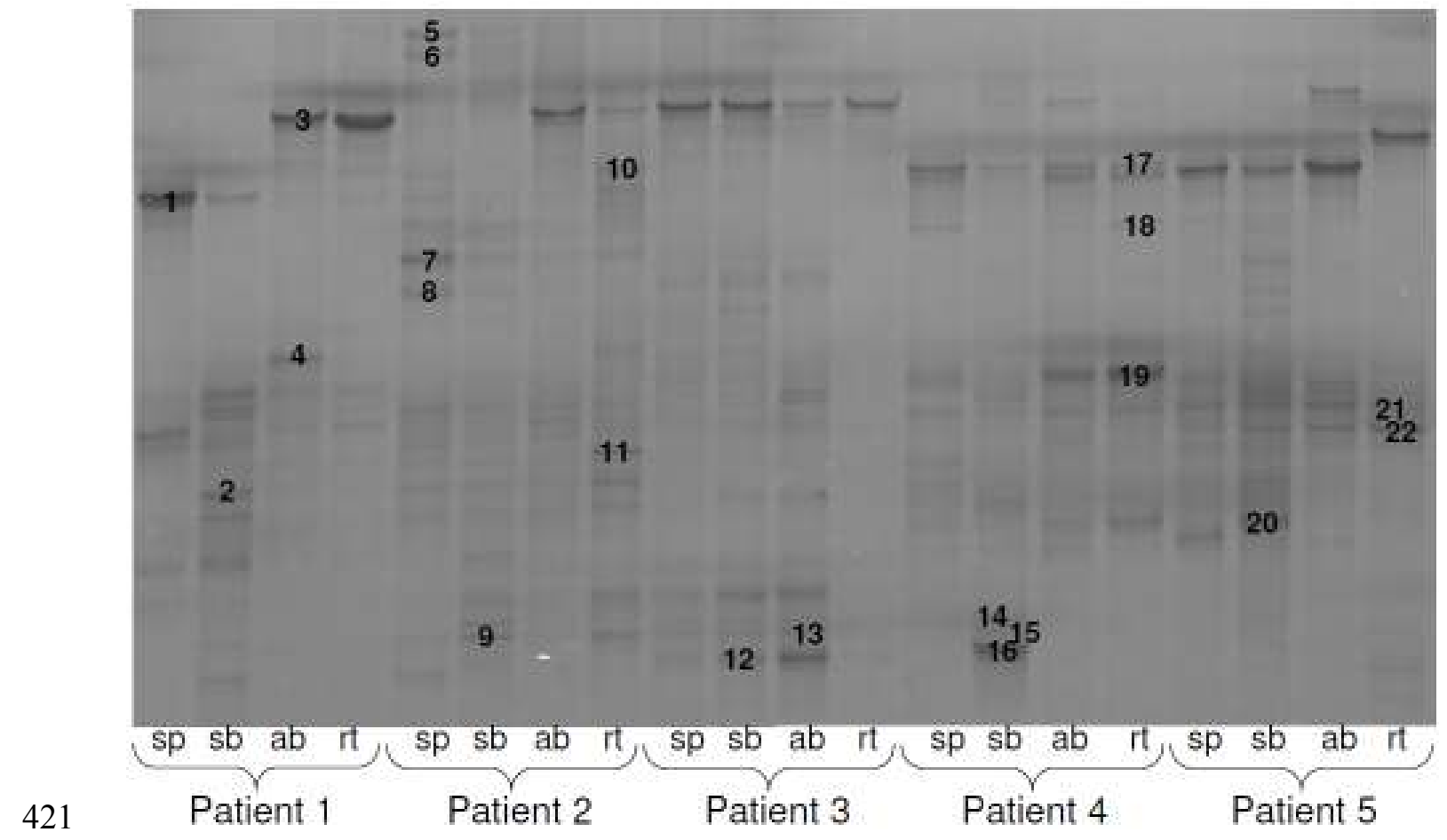


423

424

425

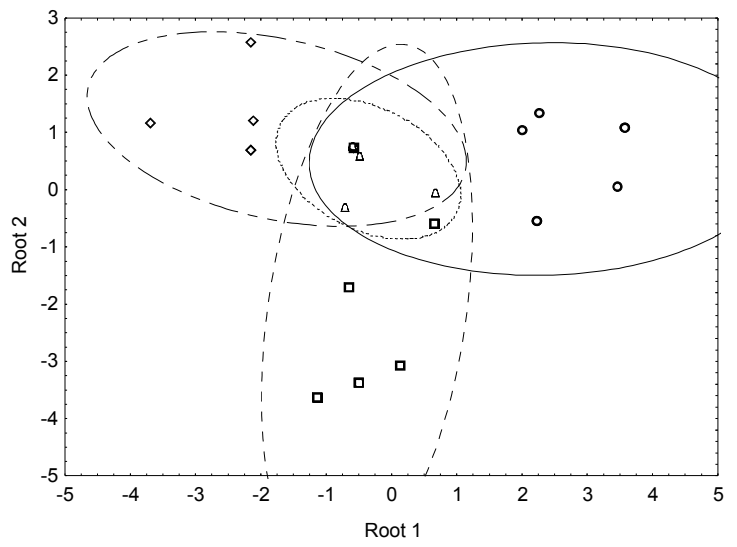

426

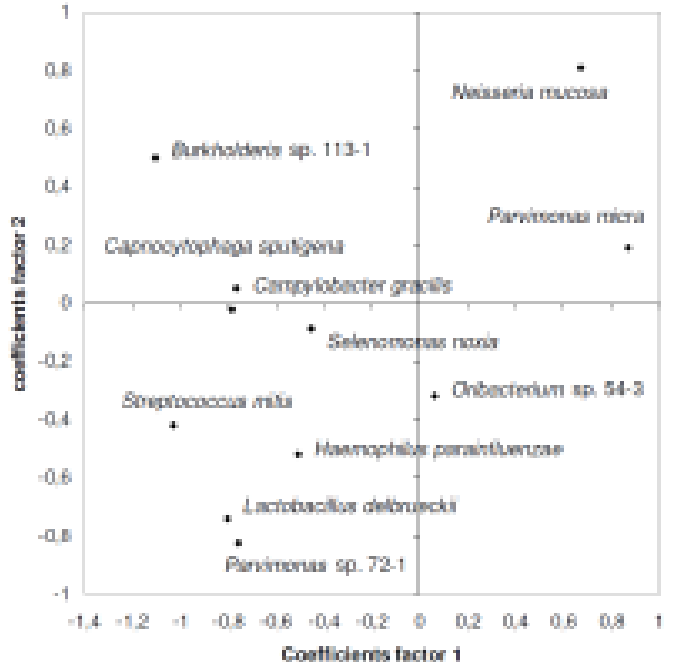

Coattidems factor 1 